\title{
Are hypersensitivity reactions to dapsone becoming more frequent?
}

\author{
W C S SMITH \\ Department of Community Medicine, Ninewells Hospital and \\ Medical School, Dundee DDI 9SY
}

Accepted for publication 9 June 1987

Summary Hypersensitivity reactions to dapsone, which were common in the late 1940s and early 1950s and then virtually disappeared, have now reappeared in the last 5-6 years. Review of the literature and a postal survey of centres using dapsone on a mass scale confirms that the reaction has reappeared. The explanation for this is unclear but may be related to the use of dapsone combined with other drugs. These reactions are rare and some centres treating large numbers of patients with dapsone have not experienced any cases. Dapsone must still be regarded as a safe preparation.

\section{Introduction}

Diaminodiphenylsulphone (dapsone) has proved a safe and effective drug, since its introduction in the 1940s, in the management of a variety of conditions from leprosy and malarial prophylaxis to dermatitis herpetiformis. The toxic effects and adverse reactions to dapsone have been well documented. In the early years after the introduction of dapsone to clinical use hypersensitivity reactions to dapsone occurred frequently but then rapidly declined. Few cases were reported between the mid 1950s and the late 1970s. However, over the last 5 or 6 years case reports of hypersensitivity reactions to dapsone have reappeared in the literature. This paper reviews the literature on hypersensitivity reactions to dapsone and presents the findings of a postal survey carried out in 1986 .

\section{Literature review}

A number of adverse reactions associated with dapsone have been reported sporadically including agranulocytosis, ${ }^{1}$ peripheral neuropathies, ${ }^{2}$ toxic epidermal necrolysis, ${ }^{3}$ hypoalbuminaemia ${ }^{4}$ phototoxicity, ${ }^{5}$ nephrotic syndrome,${ }^{6}$ and haemolysis ${ }^{7}$. The toxic effects associated with dapsone in high dosage have also been well documented and these include renal impairment, ${ }^{8}$ haemolytic jaundice,${ }^{9}$ hepatitis, ${ }^{10}$ methaemoglobinaemia, ${ }^{11}$ psychosis, ${ }^{12}$ and optic atrophy. ${ }^{13}$ The frequency of adverse reactions appears to be associated with dosage, and is higher when the dose is in excess of $100 \mathrm{mg}$ daily. There have been a number of review articles ${ }^{14,15}$ on the side-effects of dapsone but the concensus remains that dapsone is an extremely safe drug. 
Hypersensitivity reactions to sulphones were reported ${ }^{16}$ as early as 1944 when used to treat tuberculosis and later ${ }^{17}$ in the treatment of leprosy. Many adverse reactions were encountered in the early use of the sulphones and attempts were made to find a less toxic derivative. ${ }^{18}$ The earliest reports of a hypersensitivity reaction to dapsone was published in 1949 based on work in Nigeria. ${ }^{19}$ In this early description of the reaction it was thought that dapsone precipitated glandular fever. The 'illness' arose early in the treatment and was characterized by fever, lymphadenitis, splenomegaly, jaundice, abnormal liver function tests, mononucleosis, and dermatitis including generalized exfoliation. Positive Paul Bunnell tests and mononucleosis led to the diagnosis of glandular fever. The authors suggested a gradual build up in dose to $300 \mathrm{mg}$ daily was advisable to avoid this complication.

Lowe reviewed the situation in $1950^{20}$ when reporting 3 further cases of hypersensitivity reaction and advised early withdrawal of dapsone, the use of antihistamines followed by desensitization. Another publication reported liver biopsy evidence of hepatic damage in 3 cases of the reaction..$^{21}$ In 1951 the reported frequency of hypersensitivity to dapsone was $2 \%,{ }^{22}$ fatal outcomes associated with exfoliation were reported and the relation between the reaction and doses in excess of $100 \mathrm{mg}$ daily noted. In 1957 Barnes coined the name dapsone syndrome ${ }^{23}$ and advised lowering the dose of dapsone ${ }^{24}$ Other workers reported an incidence of hypersensitivity to dapsone when used on a mass scale. ${ }^{25,26}$ Case reports appeared from Malaya ${ }^{27}$ and New Guinea. ${ }^{28}$

From 1956 until 1980 there were only 2 reports of the reaction in the literature. A number of

Table 1. Case reports of hypersensitivity reaction to dapsone 1980-86

\begin{tabular}{|c|c|c|c|c|c|}
\hline Year & $\begin{array}{l}\text { Country } \\
\text { (reference) }\end{array}$ & $\begin{array}{l}\text { Patient } \\
\text { age }\end{array}$ & $\begin{array}{l}\text { Patient } \\
\text { sex }\end{array}$ & $\begin{array}{l}\text { Daily dose of dapsone } \\
(\mathrm{mg})\end{array}$ & $\begin{array}{c}\text { Other drugs } \\
\text { used }\end{array}$ \\
\hline 1980 & India ${ }^{33}$ & 40 & $\mathrm{~F}$ & 100 & - \\
\hline 1980 & India 34 & 30 & $\mathrm{~F}$ & 50 & - \\
\hline 1980 & India ${ }^{34}$ & 30 & M & 50 & - \\
\hline 1981 & * USA ${ }^{35}$ & 17 & M & 100 & - \\
\hline 1981 & $\mathrm{USA}^{36}$ & 16 & $\mathrm{~F}$ & 50 & - \\
\hline 1981 & India $^{38}$ & $?$ & $?$ & $?$ & $?$ \\
\hline 1982 & Australia $^{39}$ & 49 & $\dot{\mathrm{F}}$ & 150 & - \\
\hline 1982 & Denmark $^{40}$ & 33 & $\mathrm{~F}$ & 100 & - \\
\hline 1984 & Malaysia $^{41}$ & 17 & $\mathrm{~F}$ & 100 & Rif ampicin \\
\hline 1984 & Malaysia $^{41}$ & 18 & $\mathrm{~F}$ & 100 & - \\
\hline 1984 & Malaysia $^{41}$ & 61 & M & 200 & - \\
\hline 1984 & India 42 & $?$ & $?$ & $50-100$ & - \\
\hline 1984 & India $^{42}$ & $?$ & $?$ & $50-100$ & - \\
\hline 1985 & Thailand ${ }^{43}$ & 50 & $\dot{\mathrm{F}}$ & 50 & $\mathrm{R}+\mathrm{C}$ \\
\hline 1985 & Thailand $^{43}$ & 24 & $\mathrm{~F}$ & $?$ & $\mathrm{R}+\mathrm{C}$ \\
\hline 1985 & Thailand $^{43}$ & 35 & $\mathrm{M}$ & 100 & - \\
\hline 1985 & Thailand $^{43}$ & 45 & $\mathrm{~F}$ & 100 & - \\
\hline 1985 & Guyana $^{44}$ & - & - & $?$ & $\mathrm{R}+\mathrm{C}$ \\
\hline 1985 & Guyana $^{44}$ & - & $\mathrm{F}$ & $?$ & - \\
\hline 1985 & India 45 & 35 & M & 100 & $\mathrm{R}+\mathrm{C}$ \\
\hline 1985 & India 46 & 7 & $\mathrm{~F}$ & 25 & - \\
\hline 1985 & India $^{46}$ & 25 & M & 100 & Rif ampicin \\
\hline 1985 & India 46 & 26 & $\mathrm{~F}$ & 100 & $\mathrm{R}+\mathrm{C}$ \\
\hline 1986 & *Papua New Guinea ${ }^{47}$ & 20 & M & 100 & Clofazimine \\
\hline 1986 & Papua New Guinea ${ }^{47}$ & 20 & M & 100 & Clof azimine \\
\hline 1986 & ${ }^{*}$ India $^{48}$ & 40 & M & 100 & - \\
\hline 1986 & *USA ${ }^{49}$ & 49 & $\mathrm{~F}$ & 50 & - \\
\hline
\end{tabular}

$\mathrm{R}+\mathrm{C}$ refer to use of rif ampicin and clofazimine.

* Refers to fatal cases. 


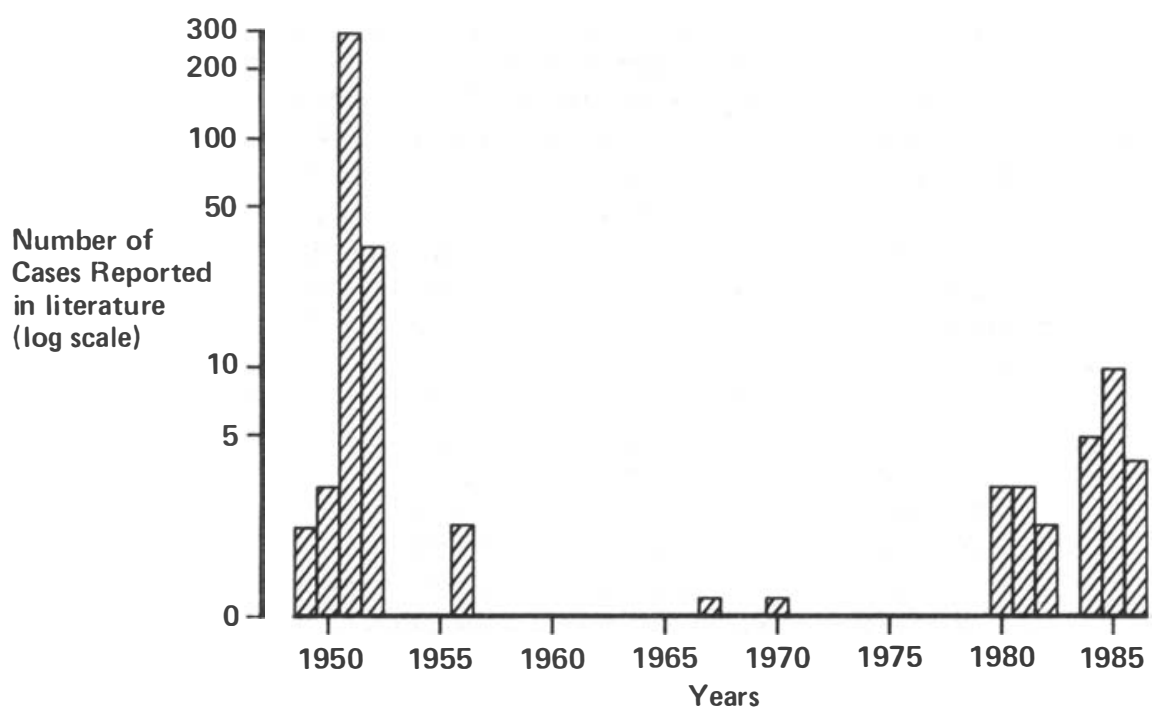

Figure 1. Number of cases of hypersensitivity reaction to dapsone reported in the literature (1949-86).

papers were published on the management of the reaction; the use of cortisone in sensitivity reaction $\mathrm{s}^{29}$ and methods of desensitization; ${ }^{30}$ but the only case reports of hypersensitivity reactions to dapsone were in $1967^{31}$ and in $1970 .{ }^{32}$ There are other reports in the literature, during this 24-year period, of jaundice associated with dapsone but they do not have the other diagnostic features of hypersensitivity and are mostly haemolytic. Then from 1980 to the present there were 27 case reports published (Table 1). The published case reports of hypersensitivity reactions to dapsone between 1949 and the present have been plotted (Figure 1).

The characteristics of the most recent 27 cases of hypersensitivity reaction were that 9 were in men and 14 in women (4 the sex was not reported) in the age range 7-50 years. Twenty-two were in leprosy patients, 2 in the treatment of dermatitis herpetiformis and one each in the treatment of acne vulgaris, psoriasis and vascalltis. In 23 out of the 27 the dose of dapsone was specified; 16 were on dapsone alone and the remainder were taking dapsone as part of the multidrug regimen (Table 1).

\section{Postal survey}

In order to estimate whether these reported cases represented all cases occurring and to estimate the frequency of occurrence of hypersensitivity a postal survey was undertaken. Leprosy centres were chosen as they were likely to be treating large numbers of new cases with dapsone. Since the syndrome occurs within 6 weeks of commencement of dapsone therapy only new cases were of interest. A total of 73 centres were included covering Asia, South and Central America and Africa and replies were received from one-third. Many centres did not treat many new cases and were thus unlikely to encounter the reaction.

Five of the 26 centres replying had recently encountered cases of hypersensitivity and provided case histories of at least 10 episodes (Table 2). These centres were in Nigeria, Korea, India, Zambia and Thailand. Four of the cases were receiving multidrug therapy with clofazimine and rif ampicin along with dapsone. Two were from previous years and associated with dapsone alone. One centre 
Table 2. Case reports of hypersensitivity reaction to dapsone from a postal survey in 1986.

\begin{tabular}{llrccc}
\hline Year & $\begin{array}{c}\text { Country } \\
\text { (reference) }\end{array}$ & $\begin{array}{c}\text { Patient } \\
\text { age }\end{array}$ & $\begin{array}{c}\text { Patient } \\
\text { sex }\end{array}$ & $\begin{array}{c}\text { Daily dose of dapsone } \\
(\mathrm{mg})\end{array}$ & $\begin{array}{c}\text { Other drugs } \\
\text { used }\end{array}$ \\
\hline 1982 & *Zambia & 16 & $\mathrm{M}$ & 100 & - \\
1982 & $*$ Zambia & 10 & $\mathrm{~F}$ & 50 & - \\
1984 & *Zambia & 46 & $\mathrm{M}$ & 100 & Rif ampicin \\
1985 & Zambia & 38 & $\mathrm{M}$ & 100 & $\mathrm{R}+\mathrm{C}$ \\
1986 & Thailand & 32 & $\mathrm{M}$ & 100 & $\mathrm{R}+\mathrm{C}$ \\
1986 & Thailand & 52 & $\mathrm{M}$ & 100 & $\mathrm{R}+\mathrm{C}$ \\
1986 & Nigeria & $?$ & $\mathrm{~F}$ & 100 & $\mathrm{R}+\mathrm{C}$ \\
1986 & Nigeria & $?$ & $\mathrm{M}$ & 100 & - \\
1986 & Nigeria & $?$ & $?$ & 100 & $\mathrm{R}+\mathrm{C}$ \\
1986 & Korea & 74 & $\mathrm{M}$ & 100 & \\
1986 & India & more than one but no details & \\
\hline
\end{tabular}

$\mathrm{R}+\mathrm{C}$ refers to use of rif ampicin and clof azimine.

* Ref ers to fatal cases.

although admitting to experiencing cases did not provide clinical details. It was not possible to give an overall estimate of the frequency of the dapsone syndrome but it varied from 0 to $2 \%$ of new cases treated.

\section{Discussion}

Review of the literature on case reports of hypersensitivity reactions to dapsone shows the reaction to be common $(2-12 \%)$ in the early years after the introduction of dapsone to clinical use, and then to virtually disappear from the literature between 1956 and 1980. The reasons for this seem unclear and no serious attempt has been made to explain the apparent disappearance. Three distinct explanations seem possible: firstly, the reaction has continued to occur but has not been recognized; secondly, the reaction has continued to occur, has been recognized but has not been reported, and finally, the reaction in fact virtually disappeared over this period. The first explanation seems unlikely due to its severity, while the second is possible having discussed the problem with many mass users of dapsone, although the sudden reappearance of case reports from 1980 onwards describe the hypersensitivity reaction as an unusual occurrence.

One conclusion from these arguments is that hypersensitivity reactions to dapsone did virtually disappear between 1956 and 1980. A proposed explanation is that the incidence of the reaction is related to dose; ${ }^{35}$ in the $1950 \mathrm{~s}$ the recommended dose of dapsone was reduced from $300 \mathrm{mg}$ to 100 $\mathrm{mg}$ daily. However, it has been argued that hypersensitivity reactions to dapsone $\mathrm{e}^{36}$ or to any other $\operatorname{drug}^{50}$ are not dose dependent. Explanations on the genetic basis of hypersensitivity reactions cannot explain sudden changes; and changes in manuf acture of dapsone have not been investigated.

The sudden reappearance of reports of the hypersensitivity reaction to dapsone since 1980 also needs to be considered. Publication bias may be a possibility but from the results of the postal survey support the fact that the syndrome is occurring widely. There has been no major increase in the use of dapsone recently but since $1982^{51}$ multidrug regimens, including dapsone, have been recommended in the treatment of leprosy. It is possible that these more complex multidrug regimens lead to wrong administration of dapsone, there is also the potential for drug interactions. About half of the recent cases of hypersensitivity since 1980 have been associated with dapsone 
monotherapy which does not support a drug interaction therapy as a complete explanation. There have been well-documented cases of hypersensitivity reactions with similar characteristics associated with clofazimine ${ }^{52}$ and rifampicin, ${ }^{53}$ this may well appear to exaggerate the frequency of hypersensitivity to dapsone. One other consideration is that dapsone is prepared in combination with pyrimethamine for malarial prophylaxis and may be dispensed in this form instead of dapsone alone,$^{54}$ adverse reactions in these circumstances may therefore not necessarily be to dapsone.

\section{Acknowledgments}

I would like to give thanks to the centres who sent me details of their experience of dapsone hypersensitivity. I would also like to thank Professor C Florey for his help in preparing this paper and to Dr A C McDougall for his encouragement. This work was supported by a grant from Arthur H Cox \& Co. Ltd of Barnstaple, Devon.

\section{References}

1 McKenna WB, Chalmers AC. Agrannlocytosis following dapsone therapy. $\mathrm{Br}$ Med J, 1958; 1: 324-5.

2 Saqueton AC, Lorinez AL, Vick NA, Hamer RD. Dapsone and peripheral motor neuropathy. Arch Derm, 1969; 100: 214-17.

${ }^{3}$ Browne SG, Ridge E. Toxic epidermal necrolysis. Br Med J, 1961; 1: 550-3.

${ }^{4}$ Kingham JGC, Swarbrick ET, Swain P, Walker JG, Dawson AM. Dapsone and severe hypoalbuminaemia. Lancet, 1979; 2: 662-4.

5 Vandersteen PK, Jordan RE. Dermatitis herpetiformis with discoid lupus erythematosus. Arch Derm, 1974; 110: $95-8$.

${ }^{6}$ Belmont A. Dapsone induced nephrotic syndrome. JAMA, 1967; 200: 262-3.

7 De Gowin RL. A review of the therapeutic and hemolytic effects of dapsone. Arch Intern Med, 1967; 120: 242-8.

${ }^{8}$ Hoffbrand BI. Dapsone and renal papillary necrosis. $\mathrm{Br}$ Med J, 1978; 1: 78.

9 Shelley WB, Goldwein MI. High dose dapsone toxicity. Br J Derm, 1976; 95: 79-82.

${ }^{10}$ Goetle DK. Dapsone induced hepatic changes. Arch Derm, 1977; 113: 1616-17.

11 Sahoo SK, Tripathy N, Debi BP. Acute fatal DDS poisoning. Lepr India, 1979; 51: 244-8.

12 Krishma Murthy K, Raja Babu KK. Toxic psychosis after accidental ingestion of dapsone-review and case report. Lepr India, 1980; 52: 443-5.

13 Homeida M, Bakikir A, Daneshmend TK. Dapsone induced optic atrophy and motor neuropathy. Br Med J, 1980; 281: 1180.

14 Graham WR. Adverse effects of dapsone. Int J Derm, 1975; 14: 494-500.

15 Millikan LE. Drug reactions to the sulphones. Arch Derm, 1971; 103: 343.

16 Pfeutze KK, Pyle MM. A severe reaction following administration of diasone. JAMA, 1944; $125: 354-5$.

17 Reyes E, Barrientos E, Rodriquez JT, Amaya AC, Peratta R. Severe reaction resembling therapeutic shock in lepers following administration of diasone. Arch Derm Syph, 1949; 59: 118-19.

18 Brownlee G. Sulphetrone: therapeutics and toxicology. Lancet, 1948; 2: 131-4.

19 Lowe J, Smith M. Chemotherapy of leprosy in Nigeria. Int J Lepr, 1949; 17: 181-95.

20 Lowe J. Treatment of leprosy with diaminodiphenylsulphone by mouth. Lancet, 1950; 1: 145-50.

21 Jelliffe DB. Toxic hepatitis caused by diamindiphenylsulphone. Lancet, 1951; 1: 1343-4.

22 Lowe J. Diaminodiphenylsulphone in the treatment of leprosy. Lancet, 1951; 1: 18-21.

23 Allday EJ, Barnes J. Toxic effects of diaminodiphenylsulphone in the treatment of leprosy. Lancet, 1951; 2: 205-6.

24 Barnes J, Barnes EJ. Liver damage during treatment with DDS. Lepr Rev, 1951; 12: 54-6.

25 Garrett AS. Mass treatment of leprosy with dapsone. Lepr Rev, 1951; 12: 47-53.

26 Garrett AS, Corcos MG. Dapsone treatment of leprosy. Lepr Rev, 1952; 13: 16-108.

27 Molesworth BD, Narayanswarin PS. Toxic effects of diaminodiphenylsulphone. Lancet, 1952; 1: 562-3.

28 Leiber DL. The mononucleosis syndrome in leprosy patients treated with sulphones. Int J Lepr, 1956; 2: 402-5.

29 Jopling WH, Cochrane RG. The place of cortisone and corticotrophin in the treatment of certain acute phases of leprosy. Lepr Rev, 1957; 28: 5-10.

30 Browne SG. Desensitization for dapsone dermatitis. Br Med J, 1963; 2: 664-6. 
31 Potter B, Szymanski FJ, Fretzin D. Erythema elevatum diutinum and sulphone hypersensitivity. Arch Derm, 1967; 95: 436-40.

32 Millikan LE, Harrell ER. Drug reactions to the sulphones. Arch Derm, 1970; 102: 220-4.

33 Lal S, Gary BR. Sulphone induced exfoliative dermatitis and hepatitis. Lepr India, 1980; 52: 302-5.

${ }^{34}$ Dutta RK. Erythema multiforme bullosum due to dapsone. Lepr India, 1980; 52: 306-9.

35 Frey HM, Gershon AA, Borkowsky W, Bullock WE. Fatal reaction to dapsone during treatment of leprosy. Ann Intern Med, 1981; 94: 777-9.

36 Tomecki KJ, Catalano CJ. Dapsone hypersensitivity. Arch Derm, 1981; 117: 38-9.

37 Editorial. Adverse reactions to dapsone. Lancet, 2: 184-5.

38 Scholastica M, Aruntratni S, Taylor PM. Dapsone hypersensitivity reaction. XII Biennial Conference of the Indian Association of Leprologists, Agra 1981.

39 Gan TE, Van der Wyden MB. Dapsone induced inf ectious mononucleosis like syndrome. Med J Aust, 1982; 1: $350-1$.

40 Kromann NP, Vilhelmsen K, Stahl D. The dapsone syndrome. Arch Derm, 1982; 118: 531-2.

41 Mohammed KN. Hypersensitivity reaction to dapsone: report from Malaysia. Lepr Rev, 1984; 5: 385-9.

42 Arunthathi, S, Jacob M, Therasa A. The dapsone syndrome. Ind J Lepr, 1984; 56: 206.

43 Joseph MS. Hypersensitivity reaction to dapsone-four cases. Lepr Rev, 1985; 56: 315-20.

44 Rose P. Adverse reactions to rif ampicin and dapsone. Lepr Rev, 1985; 56: 171.

45 Gupta CM, Bhate RD, Singh IP. The dapsone syndrome-a case report. Ind J Lepr, 1985; 57: 193-5.

46 Sharma VK, Kaurs, Kumar B. Singh M. Dapsone syndrome in India. Ind J Lepr, 1985; 57: 807-13.

47 Jamrozik K. Dapsone syndrome occurring in two brothers. Lepr Rev, 1986; 57: 57-62.

48 Smith WCS. Hypersensitivity reaction to dapsone. Lepr Rev, 1986; 57: 179-80.

49 Johnson DA, Catlan EL, Kuritsky JN, Zimmerman JH. Liver involvement in the sulf rone syndrome. Arch Intern Med, 1986; 145: 875-7.

50 Sherlock S. Prediction of hepatotoxicity due to therapeutic agents in man. Medicine, 1966; 45: 453-8.

51 WHO Study Group. Chemotherapy of leprosy for control programmes. Technical Report Series No. 675. WHO: Geneva, 1982.

52 Pavithran K. Exfoliative dermatitis after clofazimine. Int J Lepr, 1985; 53: 645-6.

53 Nyirenda R, Gih GV. Stevens-Johnson syndrome due to rifampicin. Br Med J, 1977; 2: 1189.

54 Marks J. Reactions to dapsone. Lancet, 1981; 2: 585.

\section{NEWS AND NOTES}

\section{Back numbers of Leprosy Review required}

We continue to receive a number of requests for complete sets of Leprosy Review and for individual missing numbers. The stocks of back numbers stored by LEPRA are limited. We therefore appeal to anyone who may have an unwanted collection, or odd numbers of the journal, either for donation to a bone fide applicant, or for sale. Within reasonable distance of Oxford or London we would be more than happy to arrange for collection or to negotiate payment for transport by train. Editor.

\section{Wellcome Tropical Institute Museum, London}

Professor Eldryd Parry, Director of the Wellcome Tropical Institute, has recently written as follows:

'I am writing to inf orm you about our plans to redevelop the WellcomeTropical Institute Museum (formerly the Wellcome Museum of Medical Science). You will have used the museum in the past and we hope your interest will continue after the changes have been completed.

Plans to redesign the museum and its displays are now being effected. A museum with new material is being constructed on the ground floor of the Wellcome Tropical Institute, 200 Euston Road. The present museum in the Wellcome Building, 183 Euston Road, will close on 27 November 1987.

I will write again when the new museum is ready to open, which will be in 1988. In the meantime our Malaria Exhibition will reopen in the Institute on 14 December 1987.

For further information about the museum, the exhibition (or indeed about the Institute) please contact Dr Alan Knell on 01387 4477, ext 3365, or write to: The Wellcome Tropical Institute Museum, 183 Euston Road, London NW1 2BP.' 